\title{
Design of Diesel Engine Electronic Governor Based on Model
}

\author{
Yachao ZHANG ${ }^{\mathrm{a}}$, Guanghui $\mathrm{CHANG}^{\mathrm{a}, 1}$, Long CHEN ${ }^{\mathrm{b}}$, Pan $\mathrm{SU}^{\mathrm{a}}$ \\ ${ }^{a}$ College of Power Engineering, Naval of Engineering, Wuhan 430033, China \\ b Systems Engineering Research Institute, Beijing 100000, China
}

\begin{abstract}
The electronic governor uses an algorithm to control the drive actuator to adjust the speed. It is more accurate than the traditional mechanical governor. This article starts from the research and analysis of the function of the Viking35 diesel engine electronic governor, and uses a model-based design Method, realized a type of electronic governor with simple functions, and completed its modeling, realized the control of virtual diesel engine, and analyzed its starting process, acceleration curve and load regulation curve to a certain extent The above proves the correctness of the model. This paper takes the diesel engine of a certain type of ship as the object to model and realize its speed control, and realizes the function of part of the diesel engine electronic governor during the modeling process of the controller.
\end{abstract}

Keywords. Electronic governor, simulation model

\section{Principle and Function of Electronic Governor}

The electronic speed governor is usually composed of four main parts as shown in the figure below: the controller, the actuator drive mechanism, the actuator and the speed sensor [1-2]. The controller is the core part of the electronic speed governor, and it is the part that plays the role of core speed regulation; the actuator and the actuator drive mechanism respond to the control commands issued by the controller; the speed sensor transmits the collected speed value to the control Device.

In general, most controllers use PID control[3]. The PID control algorithm is based on the difference between the controlled result and the input value $e(t)=r(t)-c(t)$.

The control linear function:

$$
u(t)=K_{p}\left[e(t)+\frac{1}{T_{i}} \int_{0}^{t} e(t) d t+T_{d} \frac{d e(t)}{d t}\right]
$$

Its transfer function:

$$
\frac{\mathrm{U}(\mathrm{s})}{\mathrm{E}(\mathrm{s})}=\mathrm{K}_{\mathrm{p}}+\mathrm{K}_{\mathrm{i}} \frac{1}{\mathrm{~s}}+\mathrm{K}_{\mathrm{d}} \mathrm{s}
$$

Where $K_{p}$ is the proportional gain, $T_{i}$ is the integral gain, $M_{e} H_{u}$ is the derivative gain, $K_{i}$ is the integral time constant, $K_{d}$ is the derivative time constant. 
The control core of the electronic governor selects ARM 32-bit high-performance Cortex-M3 core micro-controller to develop an embedded hardware system. The controller has strong model calculation capabilities, low power consumption, and low cost characteristics. The embedded system can exchange data with the external environment through the Ethernet interface or CAN bus.

\section{Establishment of Diesel Engine Model}

Model-based design can test and integrate the built model during the process of model establishment, and can reflect the control effect of the actual system [4]. It can detect and correct errors in the model in time, which greatly improves the design efficiency and reduces the design threshold The electronic governor in this article is mainly based on the performance characteristics of the 16PA6V-280STC diesel engine for the design of the electronic governor. In the design of the electronic governor model, the diesel engine only has the function of inputting the speed and verifying the governor control effect, and the complete establishment of a digital diesel engine model requires a lot of complex calculations and model parameter settings, so only in the process of model building The part that retains the corresponding functions of the diesel engine is simplified to a model in which the throttle opening adjusts the fuel quantity and then the speed.

\subsection{Mathematical Model of Diesel Engine}

The instantaneous output torque of a supercharged diesel engine is

$$
\begin{gathered}
\mathrm{M}_{\mathrm{i}}=\mathrm{H}_{\mathrm{u}} \mathrm{g}_{\mathrm{c}} \eta_{\mathrm{i}} / \tau \pi \\
\mathrm{M}_{\mathrm{e}}=\mathrm{M}_{\mathrm{i}} \cdot \eta_{\mathrm{m}}
\end{gathered}
$$

Where $M_{i}$ is the Diesel engine indicated torque, $M_{e}$ is the Diesel engine effective torque, $H_{u}$ is the fuel low calorific value, In this article the value is $4.27 \times$ $10^{7} \mathrm{~J} / \mathrm{kg}, \eta_{i}$ is Indicated efficiency of diesel engine, $\eta_{m}$ is Mechanical efficiency of diesel engine.

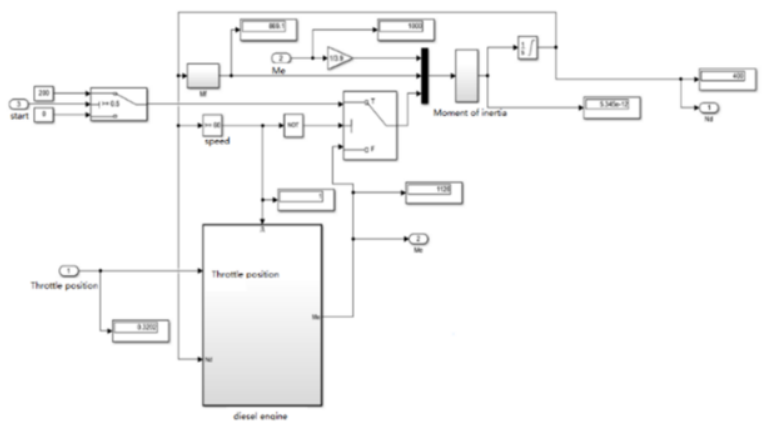

Figure 1. Diesel engine model

From the above figure 1, the output torque of a supercharged diesel engine is mainly related to the fuel injection volume per cycle and the effective efficiency of the 
diesel engine. When the charge air cannot cooperate in time, it will cause the effective efficiency of the diesel engine and the effective torque of the diesel engine to decrease.

The excess air coefficient is the ratio of the actual amount of air charged to burn 1 $\mathrm{kg}$ of fuel to the theoretical amount of air required for complete combustion of $1 \mathrm{~kg}$ of fuel, which is

$$
\alpha=\frac{\mathrm{G}_{\mathrm{tr}}}{\mathrm{G}_{\mathrm{f}} \cdot \mathrm{L}_{0}}
$$

Where $L_{0}$ is the theoretical amount of air required to burn $1 \mathrm{~kg}$ of fuel

$G_{f}$ is the fuel injection volume per unit time.

$$
\mathrm{G}_{\mathrm{f}}=\frac{\mathrm{g}_{\mathrm{c}} \cdot \mathrm{N}_{\mathrm{d}}}{30 \tau}
$$

$G_{t r}$ is the diesel engine intake air flow, the unit is $\mathrm{km} / \mathrm{s}$

$$
\mathrm{G}_{\mathrm{tr}}=\frac{\mathrm{i} \cdot \mathrm{V}_{\mathrm{s}} \cdot \mathrm{N}_{\mathrm{d}} \cdot \mathrm{p}_{3} \cdot \eta_{\mathrm{v}}}{120 \cdot \mathrm{R} \cdot \mathrm{T}_{\mathrm{i}}}
$$

Where $\tau$ is the number of strokes of diesel engine, $\tau=4, i$ is the number of cylinders, $i=16, V_{s}$ is the total cylinder volume, $T_{i}$ is the diesel engine intake temperature which is the central cooler outlet temperature, $P_{3}$ is the diesel engine intake pressure, $N_{v}$ is the Volumetric efficiency.

Rely on the empirical formula of a four-stroke supercharged diesel engine:

$$
\eta_{\mathrm{v}}=0.976+2.1 \times 10^{-7} \cdot \mathrm{N}_{\mathrm{d}}-2.7 \times 10^{-10} \cdot \mathrm{N}_{\mathrm{d}}^{2}
$$

Diesel engine indicated efficiency $\eta_{i}$ is a function of diesel engine speed $N_{d}$ and excess air coefficient $\alpha$, according to the basic characteristics of diesel engine universal characteristic curve

$$
\eta_{\mathrm{i}}=\mathrm{a}_{0}\left[\left(\mathrm{~N}_{\mathrm{d}}-\mathrm{N}_{\mathrm{d} 0}\right)^{2}+\mathrm{a}_{1}^{2}\left(\alpha-\alpha_{0}\right)^{2}\right]+\mathrm{a}_{2}
$$

Where $\mathrm{N}_{\mathrm{d} 0}, \alpha_{0}$ are the Diesel engine speed and excess air coefficient corresponding to the maximum indicated efficiency of the diesel engine

\subsection{Diesel Engine Dynamic Model}

The dynamic equation of the diesel engine is

$$
\frac{\pi \mathrm{I}_{\mathrm{e}}}{30} \frac{\mathrm{dN}_{\mathrm{d}}}{\mathrm{dt}}=\mathrm{M}_{\mathrm{e}}-\mathrm{M}_{\mathrm{f}}-\mathrm{M}_{\mathrm{l}}
$$

Where $N_{d}$ is diesel engine speed, $I_{e}$ is the moment of inertia from the shaft of the main engine to the pump wheel of the fluid coupling, $M_{e}$ is the engine effective torque, $\mathrm{M}_{\mathrm{l}}$ is the load torque, $\mathrm{M}_{\mathrm{f}}$ is the friction torque from the rotating shaft of the diesel engine to the pump wheel of the fluid coupling (figure 2). 


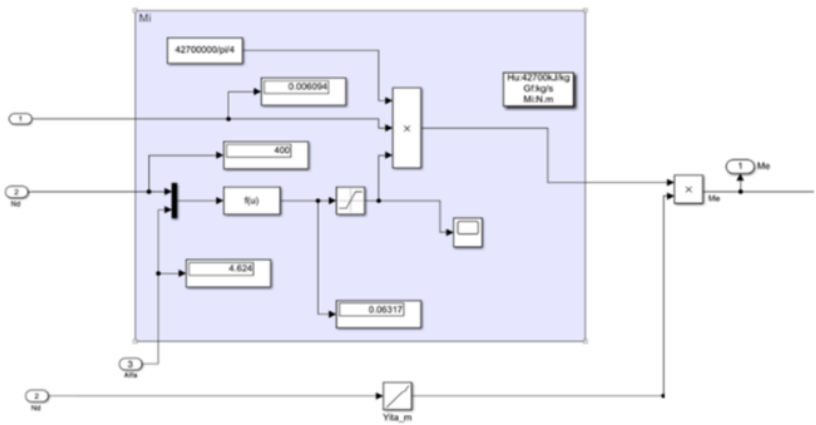

Figure 2. Diesel engine mechanics model

\section{Software Development of Electronic Speed Governor Based on Model}

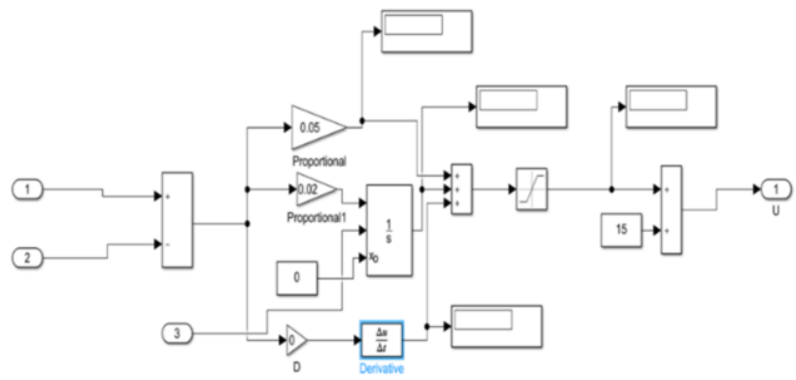

Figure 3. PID controller model

In this governor model (figure 3), the speed controller adopts PID control. Since the digital model of the diesel engine is not a linear model, it is a nonlinear model of the speed obtained by integrating the acceleration obtained by dividing the total torque by the fuel work. The PID module with it is not applicable, but the proportional and differential modules are used to build the PID controller.

The core of the model lies in the speed control. InPort1 is the given speed, InPort2 is the actual speed of the diesel engine. The given speed increases the throttle and drives the speed of the main engine to rise. The speed of the diesel engine is fed back to the speed controller, and the whole system is connected in series. A closed loop. When there is a difference between the two, as time increases, the integral term will increase, which means that as time grows, even if the error is small, the integral term will continue to increase, pushing the governor controller to make steady-state errors. Reduce to control the position of the throttle so that the speed of the diesel engine tends to be consistent with the given value. 


\subsection{Start-Stop Process Control}

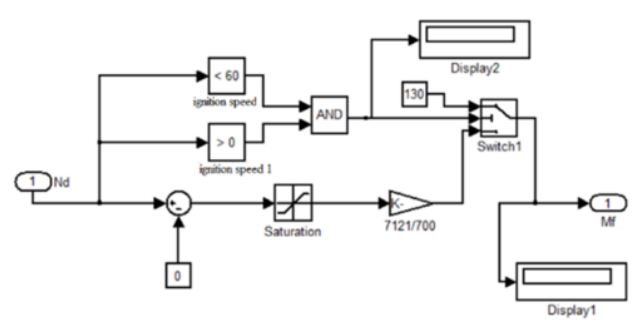

Figure 4. Shutdown process control model

This type of diesel engine mainly adopts air starting during the starting process, that is, the air compressor is used to give a starting torque to the stationary diesel engine, so that the speed of the diesel engine slowly rises. At low speeds, the gas pressure and temperature in the cylinder of the diesel engine cannot meet the combustion requirements, and the fuel automation effect is also poor. When the speed reaches its ignition speed, the fuel in the cylinder starts to burn and does work externally under the action of pressure and temperature. Start to speed up. Therefore, in this model, the ignition speed is set to $60 \mathrm{rpm}$. Before this speed, the diesel engine is driven by an air pressure torque of $200 \mathrm{~N} \cdot \mathrm{m}$. When the speed reaches $60 \mathrm{rpm}$, the fuel starts to burn and the diesel engine speed rises.

In figure 4, the shutdown of the diesel engine uses a parking switch to stop and disconnect the PID control effect to achieve the effect of cutting off the fuel. At the same time, in the setting of the friction torque $\mathrm{M}_{\mathrm{f}}$ its size is proportional to the speed. The lower the speed, the more torque. This is obviously inconsistent with the actual situation. Therefore, the friction torque $\mathrm{M}_{\mathrm{f}}$ is set to $130 \mathrm{~N} \cdot \mathrm{m}$ at low speed, so that the diesel engine can be stopped normally.

\subsection{Diesel Engine Loading Process}

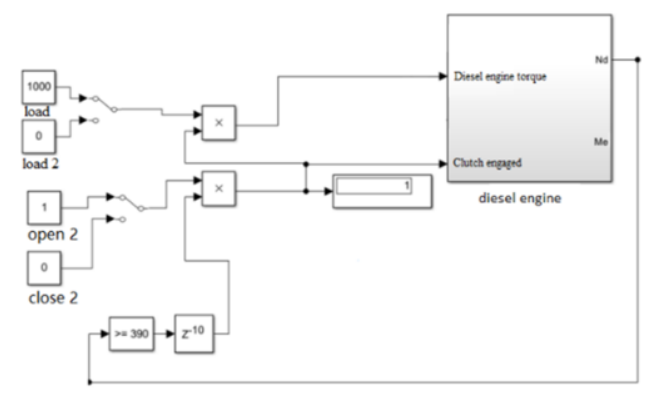

Figure 5. Load control model

Generally speaking, the starting process of a is no-load starting. Therefore, in figure 5, the clutch engagement signal can be connected only after the speed is greater than 390 rpm and a delay of 2 seconds, that is, when the diesel engine speed is stable above the idle speed. The value of the moment of inertia I_e also changes from the moment of inertia of the body itself to the moment of inertia after the clutch is attached. And only when the clutch is engaged can the load be effectively connected to the diesel engine. 


\section{Simulation and Analysis of Controller Dynamic Performance}

\subsection{Simulation Analysis of Starting Process}

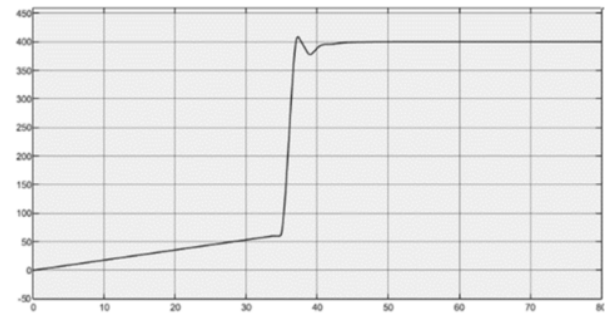

Figure 6. Speed of diesel engine during starting

As shown in the figure 6 , the model uses air pressure torque to provide kinetic energy before the speed reaches $60 \mathrm{rpm}$. The speed rises slowly, and reaches the ignition speed at about $35 \mathrm{~s}$. The diesel engine starts to ignite and burns. The speed rises sharply under the action of gas and stabilizes at about $45 \mathrm{~s}$. At idle speed. The speed curve in the starting process is not much different from the actual speed, and a better simulation can be done in this model

\subsection{Simulation Analysis of Loading Process}

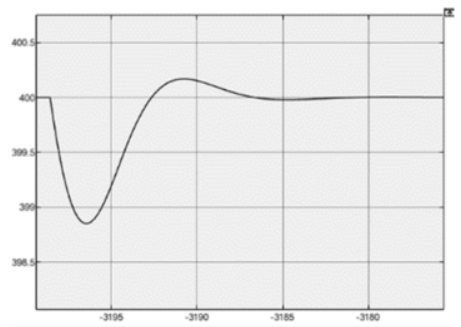

Figure 7. Rotation speed simulation diagram of $1000 \mathrm{~N} \cdot \mathrm{m}$ load loading process

In general, diesel engines are mainly based on speed control, so the speed of the speed response when the load changes is an important basis for judging the performance of the diesel engine. In figure 7, this model uses the loading process of $1000 \mathrm{~N} \cdot \mathrm{m}$ and $10000 \mathrm{~N} \cdot \mathrm{m}$ load torque to compare the model. Response speed for analysis.

In general, the modified model has a good ability to adjust load changes and can meet the requirements of a propulsion host or a generator host. However, because the detailed friction and inertia parameters are different from the actual, the actual control effect will be deviated. 


\subsection{Simulation Analysis of Speed Change Process}

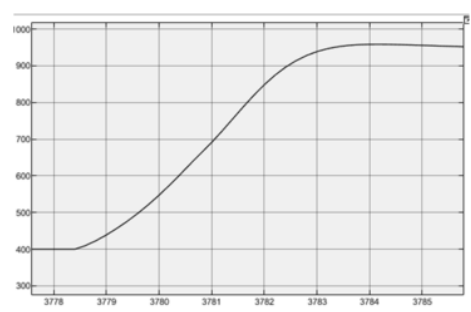

Figure 8. Acceleration curve simulation diagram

When the diesel engine is used as the propulsion host, the speed change process is required to be fast and stable to meet the maneuverability requirements of the ship. Therefore, in this section, the acceleration process of the model will be analyzed using the no-load condition of the model.

The acceleration curve as shown in the figure 8 is stable and quick to adjust, but because it is an acceleration model under ideal no-load conditions, the actual acceleration process will be slower than this curve, but its stability will not be affected.

\section{Conclusion}

This article briefly analyzes the principle of the electronic governor and its main control algorithms, interprets the functions of the Viking35 electronic governor, and uses the concept of model-based design on this basis, using Simulink as the platform and relying on 16PA6V-280STC Design and build a digital diesel engine and its electronic governor. Through the realization of the process of controlling the diesel engine, the electronic governor controlled by PID algorithm is designed, and part of the function of the Viking35 electronic governor is realized. The simulation results of the diesel engine starting, loading and shifting process can meet the requirements.

\section{References}

[1] Luo Zihua, Huang Daming, Wei Zhikang, Yao Qihong. A brief introduction of governors for diesel engines[J]. Tractor \& Farm transporters, 2007(02):12-13.

[2] Gu Linlin, Zhang Jundong. Simulation of diesel engine electronic governor baed on fuzzy PID controller[J]. Journal of Dalian Maritime University,2014,40(01):57-60+65.

[3] Vagia, M., Nikolakopoulos, G., Tzes, A.: Design of a robust PID-control switching scheme for an electrostatic micro-actuator. Control Eng. Pract. 16(11), 1321-1328 (2008)

[4] Hansen, S.G., Koch, D., Tørresen, J.: High speed partial run-time reconfifiguration using enhanced ICAP hard macro. In: Reconfifigurable Architectures Workshop (RAW) co-located with IEEE International Parallel and Distributed Processing (IPDPS), pp. 174-180, May 2011 